\title{
Излучатели терагерцового диапазона на основе полупроводниковых наноструктур
}

\author{
В.И. Гавриленко \\ Институт физики микроструктур РАН-филиал Федерального исследовательского иентра \\ Институт прикладной физики Российской академии наук, 603950, Н.Новгород, ГСП-105 \\ эл.nочта: gavr@ipmras.ru
}

DOI 10.34077/RCSP2019-73

Проблема создания компактных источников излучения дальнего ИК диапазона продолжает оставаться актуальной. В диапазоне 1-5 ТГц и свыше $15 \mathrm{THz}(\lambda=20$ мкм) наиболее эффективными излучателями являются квантовые каскадные лазеры (ККЛ) [1]. В интервале 5-15 ТГц в большинстве используемых для создания ККЛ полупроводников А3В5 наблюдается сильное фононное поглощение, препятствующей лазерной генерации. Имеются отдельные сообщения о лазерной генерации в этом диапазоне на основе графена и III-нитридов, где частоты оптических фононов значительно выше, однако эти работы пока не получили подтверждения. В докладе будет сделан обзор последних результатов по продвижению в дальний ИК диапазон ККЛ на основе полупроводниковых систем отличных от GaAs/AlGaAs [2-4] и межзонных лазеров на основе узкозонных твердых растворов $\mathrm{PbSnSe}$. B PbSnSe частоты оптических фононов, напротив, низки, а симметрия законов дисперсии электров и дырок подавляет безызлучательную межзонную ожерекомбинацию, что позволило продемонстрировать лазерную генерацию вплоть до длины волны 50 мкм $(f=6$ ТГц) [5]. Показано, что лазеры на основе PbSnSe могут быть использованы для лабораторной спектроскопии, однако их характеристики радикально ограничены технологией роста материала: типичная концентрация электрически активных собственных дефектов составляет $10^{18}$ $10^{19}$ см-3 и может быть снижена максимум до $10^{17} \mathrm{~cm}^{-3}$ путем многомесячного отжига.

Альтернативной узкозонной полупроводниковой системой с «графеноподобным» (близким к линейному) законом дисперсии являются квантовые ямы (КЯ) $\mathrm{HgTe} / \mathrm{CdHgTe}$, выращиваемые в ИФП СО РАН методом молекулярно-лучевой эпитаксии с концентрацией остаточных примесей на уровне $10^{14} \mathrm{~cm}^{-3}$. Как в PbSnSe, в $\mathrm{CdHgTe}$ частоты оптических фононов ниже, чем материалах A3B5, a симметричные законы дисперсии электронов и дырок подавляют оже-рекомбинацию. Все это позволяет рассчитывать на создание лазеров, работающих в широком интервале длин волн от 3 до 50 мкм (вплоть до $f=6$ ТГц). В докладе будут представлены результаты наблюдения стимулированного излучения вплоть до длины волны 20 мкм [6] и результаты исследований характеристик материала на длинах волн до 50 мкм, подтверждающие сделанный вывод.

\section{Лumepamypa}

[1] M.S. Vitiello G. Scalari, B. Williams, P. De Natale, Opt. Express, 23, 5167 (2015).

[2] A. N. Baranov, Z. Loghmari, M. Bahriz, R. Teissier Long wavelength InAs- based quantum cascade lasers. Proc. 3rd Int. Conf. Terahertz and Microwave radiation : Generation, Detection and Applications, N.Novgorod, October 22-25, 2018, Inst. Appl. Phys., S4.2.1.

[3] Loghmari, Z., Bahriz, M., Teissier, R., Baranov, A.N. InAs-based quantum cascade lasers emitting close to $25 \mu \mathrm{m}$. Electronics Lett. 55(3), $144-146$ (2019).

[4] K. Ohtani, M. Beck, M. J. Süess, J. Faist, A. M. Andrews, T. Zederbauer, H. Detz, W. Schrenk, G. Strasser. Far-Infrared Quantum Cascade Lasers Operating in the AlAs Phonon Reststrahlen Band. ACS Photonics 3(12), 2280-2284 (2016).

[5] К.В. Маремьянин, А.В. Иконников, Л.С. Бовкун, В.В. Румянцев, Е.Г. Чижевский, И.И. Засавицкий, В.И. Гавриленко. ФТП 52(12), 1486 (2018).

[6] S.V.Morozov, V.V.Rumyantsev, M.A.Fadeev, M.S.Zholudev, K.E.Kudryavtsev, A.V.Antonov, A.M.Kadykov, A.A.Dubinov, N.N.Mikhailov, S.A.Dvoretsky, V. I. Gavrilenko. Appl. Phys. Lett. 111, 192101 (2017). 